\title{
Correction to: 15-Minute City in Urban Regeneration Perspective: Two Methodological Approaches Compared to Support Decisions
}

Ginevra Balletto (D), Michèle Pezzagno (D), and Anna Richiedei (D)

\begin{abstract}
Correction to:
Chapter "15-Minute City in Urban Regeneration Perspective: Two Methodological Approaches Compared to Support

Decisions" in: O. Gervasi et al. (Eds.): Computational Science and Its Applications - ICCSA 2021, LNCS 12953, https://doi.org/10.1007/978-3-030-86976-2_36
\end{abstract}

In the originally published version, the authors of the paper "15-Minute City in Urban Regeneration Perspective: Two Methodological Approaches Compared to Support Decisions" had their first and last names inverted. The correctly written names are "Balletto, Ginevra", "Pezzagno, Michéle", and "Richiedei, Anna". Author names has been updated in chapter. 